\title{
Ações afirmativas e comunicação organizacional: disputas discursivas na Universidade Federal do Rio Grande do Sul
}

Affirmative actions and organizational communication: discursive disputes at the Universidade Federal do Rio Grande do Sul

Acciones afirmativas y comunicación organizacional: disputas discursivas en la Universidad Federal do Rio Grande do Sul 


\section{Resumo}

Este estudo analisa a disputa em torno da política de ações afirmativas da Universidade Federal do Rio Grande do Sul à luz da comunicação organizacional e do discurso organizacional. Acionamos as noções de organização comunicante e de cenas de dissenso como elementos da comunicação nas organizações para pensar as disputas discursivas que as atualizam e permitem o acesso a relações de poder e processos identitários. Verificou-se que determinados sujeitos necessitam lutar para conquistar espaço nos debates e nos processos de identidade da organização.

\section{PALAVRAS-CHAVE: COMUNICAÇÃO ORGANIZACIONAL・DISCURSO ORGANIZACIONAL・UNIVERSIDADE・AÇÕES AFIRMATIVAS.}

\section{Abstract}

This study analyzes the dispute over affirmative action policies in the Universidade Federal do Rio Grande do Sul in the light of organizational communication and organizational discourse. The discursive disputes that update the organization and allow access to power relations and identity process were discussed based on the notions of communicative organization and scenes of dissent as elements of organizational communication. The results indicate that certain subjects need to fight for gaining space in debates and identity processes within the organization.

KEYWORDS: ORGANIZATIONAL COMMUNICATION • ORGANIZATIONAL DISCOURSE・UNIVERSITY • AFFIRMATIVE ACTIONS.

\section{Resumen}

Este estudio analiza la disputa sobre la política de acciones afirmativas de la Universidad Federal do Rio Grande do Sul bajo la luz de la comunicación y el discurso organizacional. Se emplean las nociones de organización comunicante y las escenas disidentes como elementos de comunicación en las organizaciones para pensar en las disputas discursivas que la actualizan y permiten el acceso a relaciones de poder y procesos de identidad. Se encontró que ciertos sujetos necesitan luchar para ganar espacio en el debate y en los procesos de identidad de la organización. 


\section{INTRODUÇÃO}

A luta por medidas que garantam o acesso dos autodeclarados negros a todos os níveis de ensino remonta aos anos 1970 e ao surgimento de movimentos sociais negros que tinham como pauta a afirmação dessa identidade e a denúncia do mito da igualdade racial, dominante no imaginário social brasileiro (Guimarães, 2003). Como desdobramento dessas pautas surge, nos anos 1990, o tema das ações afirmativas (Domingues, 2005), num cenário de extrema desigualdade racial1. Um marco importante dessa luta é a III Conferência Mundial contra o Racismo, a Xenofobia e as Intolerâncias Correlatas, realizada em Durban, África do Sul, em 2001, que contou com o Brasil como signatário.

No seu plano de ação, a III Conferência Mundial recomendava, entre outras medidas, que os Estados desenvolvessem ações afirmativas ou medidas de ação positivas, para promoverem o acesso de grupos de indivíduos que são ou podem vir a ser vítimas de discriminação racial. (Domingues, 2005, p.167)

A pressão social levou o governo brasileiro, em 2002, a lançar o Programa Nacional de Direitos Humanos II, que indicava a adoção de políticas de caráter compensatório para a eliminação da discriminação racial e a promoção da igualdade de oportunidades. A partir daí, foi desenvolvida uma série de políticas em diferentes ministérios e nas esferas municipais e estaduais.

As ações afirmativas chegaram ao ensino superior a partir de 2003, com experiências pioneiras no Rio de Janeiro. Com 0 passar dos anos, políticas de variados formatos foram implementadas nas universidades públicas do país até a Lei Federal nำ12.711, de 29 de agosto de 2012, tornar obrigatória a reserva de vagas em todas as universidades e institutos federais. Apesar de o caráter racial da reserva de vagas ser o que provocou maior polêmica, as cotas têm como primeiro critério de corte um dado social, pois são destinadas integralmente a oriundos de escolas públicas.

A criação e o desenvolvimento da política de cotas em âmbito local constituem uma reorganização das universidades federais - organizações reservadas a pequena parcela da população - e representa a abertura do sistema, a partir do processo de luta, para democratização racial e social dos alunos dessas instituições.

A Universidade Federal do Rio Grande do Sul (UFRGS) esteve entre as primeiras universidades a criar cotas com sua política baseada em critérios sociais - estudantes oriundos do ensino público - e raciais - autodeclarados negros - aprovada em 2007. A aprovação contou com mobilizações dentro e fora da universidade, em que se destacaram movimentos favoráveis e contrários à política, sendo que os argumentos pró-inclusão eram contrapostos à defesa da excelência (Grisa, 2009). 0 contexto político-social favorável e a pressão de movimentos locais levaram à institucionalização do debate na UFRGS, em 2005, e à criação do Grupo de Trabalho de Ações Afirmativas (Silva; Campos, 2019), que, no ano seguinte, foi ampliado com 0 ingresso de entidades do movimento negro. A proposta seguiu para o Conselho Universitário, que aprovou a medida.

A implementação promoveu o ingresso de alunos de perfil diferente do amplamente hegemônico no campus da universidade. Tal processo de democratização racial e social vem sendo marcado por conflitos organizacionais que constantemente resultam em cenas de dissenso, como protestos, ocupações e debates pela mídia. As ações afirmativas configuram um tema que aciona uma série de processos de identidade e diferença em várias esferas da organização, evidenciando disputas discursivas sobre a identidade organizacional.

1 Para um levantamento da desigualdade racial no acesso às universidades públicas do país, anterior às cotas, ver Guimarães (2003). 
Na esteira da reflexão sobre os estudos de discurso na comunicação organizacional (Baldissera; Mafra, 2019), propomos neste artigo a análise de uma cena de dissenso relacionada à disputa sobre a política de ações afirmativas na UFRGS como objeto discursivo revelador de jogos de forças, da emergência de sujeitos e de processos identitários. Tal visada é possibilitada pela noção de organização comunicante, que expande o olhar para a comunicação não oficial, e pela apropriação para este campo da noção de cenas de dissenso (Marques; Mafra, 2014), momentos-chave em que podem se fazer ouvir os imprevistos. Como afirmam Baldissera e Mafra (2019, p.3), a tensão da comunicação organizacional pelas "lentes do discurso é movimento reflexivo que se investe, inevitavelmente, do intuito de se problematizar aspectos atinentes aos complexos processos de emergências de identidades, processos estes atravessados por disputas e relações de poder".

Este estudo se insere no debate sobre a interação entre discurso, comunicação organizacional e identidade. Acompanhamos a indicação de Baldissera e Mafra (2019, p.9), quando afirmam que, "nos ambientes organizacionais contemporâneos, questões que atravessam as interações nos sistemas organizacionais, na forma de disputas políticas e identitárias, tornamse problemáticas preciosas para serem apanhadas em seus aspectos discursivos".

O problema que move este artigo pode ser sintetizado na seguinte pergunta: como os processos identitários constituem e são constituídos em disputas discursivas, no âmbito organizacional? Para tanto, nossa análise recai sobre uma ocupação da reitoria da UFRGS, realizada em protesto contra uma medida restritiva às ações afirmativas. Nossa investida busca compreender as dinâmicas identitárias dessa disputa, reconhecendo a tentativa de fechamento do dissenso, pelo lado da organização comunicada (Baldissera, 2009), e de atualização e redefinição da identidade pelo lado do sujeito emergente, visível pela dimensão da organização comunicante. Para tanto, analisamos, em publicações no site da instituição e no Facebook do movimento de ocupação, as marcas discursivas que remetem a processos de identidade e diferença.

Além desta introdução, este artigo conta com uma sessão teórica, em que trabalhamos os conceitos de organização na perspectiva relacional, cenas de dissenso e organização comunicante e debatemos a relação entre discurso e comunicação organizacional. Ademais, fazemos a análise das materialidades que conformaram o embate discursivo em tela. Nas considerações finais, retomamos as principais contribuições do trabalho.

\section{COMUNICAÇÃO E DISCURSO ORGANIZACIONAL}

As organizações, vistas em perspectiva relacional, são, a um só tempo, o organizado, o ordenado e o estável, que guardam em si o desordenado, o desorganizado e o instável (Baldissera, 2007). Numa perspectiva sistêmica, as estruturas sociais surgem como padrões de relacionamento. "Esses padrões conduziriam a uma grande variabilidade, não fosse a existência de forças que a reduzem: pressões do ambiente, valores e expectativas compartilhadas, imposição de regras" (Misoczky, 2003, p.4), dispositivos que limitam a variabilidade do comportamento social. Misoczky (2003) afirma que, nos sistemas sociais, o papel desempenhado pelos membros se desenvolve em um comportamento prescrito e sancionado por normas, enraizadas como valores. As bases de integração do sistema são a interdependência funcional dos papéis, a coesão depreendida das normas e valores e a centralidade nos objetivos do sistema. 0 sistema pode ser descrito a partir de suas propriedades estáveis, mas também como um processo em que há mudança nas relações entre essas propriedades. Por essa ótica, atenta às mudanças e às continuidades, a organização está em permanente tensão, "assim, ao mesmo tempo, a organização, como sistema autoeco-organizado, fecha-se estrategicamente para construir-se e instituir-se como uma dada coerência/ordenação" (Baldissera, 2007, p.231), e abre-se em processo de atualização.

A relação entre o sujeito e a cultura organizacional se estabelece em níveis de tensão e relações de poder. "Ao entrar em relações comunicacionais, de alguma forma, os sujeitos perturbam a significação de mundo já-construída, já-tecida, já- 
estabelecida, seja para reafirmá-la, corroborá-la, negá-la e/ou transformá-la" (Baldissera, 2017, p.70). Nesse sentido, Mafra e Marques (2019) apontam que a comunicação organizacional se constitui na tensão perturbação-ordenação, pois "as diferenças, ainda que incorporadas e diluídas num todo identitário, são forças que movem/sustentam/provocam os próprios pontos de identificação supostamente estáveis, nos ambientes relacionais organizacionais" (p.12).

Tal concepção dialoga com Silva (2000), quando este aponta que a identidade se estabelece pela diferença, na relação entre os que são identificados e os que não são. 0 autor descreve a identidade, assim como a diferença, como o resultado de um "processo de diferenciação". Para sustentar essa posição, retoma o funcionamento da linguagem, apontando que o signo é, em si, a ilusão da presença e, ao mesmo tempo, a comprovação da ausência; ou seja, o signo, em vez de um ser é um não ser, o que representa a primazia da diferença. A identidade está sempre ligada a uma forte separação entre nós e eles. Essa demarcação de fronteiras, essa separação e distinção supõem e, ao mesmo tempo, afirmam e reafirmam, relações de poder.

Para pensar a participação dos movimentos sociais e suas práticas políticas-discursivas em processos identitários no contexto organizacional, apontamos como relevante a noção de cenas de dissenso, produzida por Rancière e aportada à comunicação organizacional por Marques e Mafra (2014). De acordo com estes autores, o diálogo que ocorre nesses acontecimentos, na perspectiva de Rancière, "é o evento fundante de comunidades políticas, nas quais um sentido de público é construído pela aparência e pelo engajamento comunicativo e agonístico" (Marques; Mafra, 2014, p. 4). A constituição das comunidades políticas a partir dessas cenas indica a imprevisibilidade dessas circunstâncias para o controle da organização.

É sob esse ângulo que podemos nos apropriar da noção de cenas de dissenso elaborada por Rancière para afirmar que, nos contextos organizacionais, o diálogo opera sob uma pretensa igualdade moral e política mobilizada por ações que visam a integração e colaboração - ainda que tais contextos sejam comumente marcados por tensões diversas e por uma pluralidade desigual e estilhaçada de vozes. (Marques; Mafra, 2014, p.4)

0 dissenso configura-se como um desacordo em relação a sentidos específicos disputados, mas também a respeito das próprias bases da situação, das formas de enquadrar os fatos e da definição dos sujeitos que podem ou não participar do debate. As cenas

permitiram a redisposição de objetos e de imagens que formam o mundo comum já dado, ou a criação de situações aptas a modificar nosso olhar e nossas atitudes com relação ao ambiente coletivo, questionando uma ordem dominante que apaga conflitos, diferenças e resistências. (Marques; Mafra, 2014, p.11)

No caso das ações afirmativas, é a partir da cena que os movimentos sociais negros, afastados de espaços institucionais, podem irromper ao debate, tornando-se sujeitos das políticas, em disputa com as forças que buscam cessar sua existência efetiva.

0 estudo da cena de dissenso que visualizamos neste artigo parte da ideia de que os sujeitos em luta produzem discursos. As práticas discursivas imbricadas nas disputas no terreno organizacional contêm as marcas das disputas e permitem acessar as mudanças que a identidade organizacional sofre no processo de fechar-se e abrir-se ao novo. A mirada discursiva leva em consideração as relações entre sujeitos nos contextos sócio-históricos, articulando "os processos e as condições de produção da linguagem" e possibilitando destacar a "relação estabelecida pela língua com os sujeitos que a falam e as situações em que se produz o dizer" (Orlandi, 2009, p.16).

Uma das principais referências da análise de discurso francesa (ADF), Pêcheux (1997) aponta claramente a relação intersubjetiva como constitutiva do discurso, pois o discurso é entendido como efeito de sentido entre lugares de sujeito em determinada formação social. A noção de formação discursiva do autor francês busca costurar o discurso na estrutura econômico-social. 
Segundo Lijterman (2017), após críticas relacionadas à pouca margem para agência dos sujeitos, nos estudos de discurso, ganhou força a noção de acontecimento discursivo. 0 reforço ao acontecimento não recoloca o discurso como ato individual, mas promove uma relação dialética entre 0 ato discursivo e a estrutura. 0 próprio Pêcheux aborda o risco de "perder" 0 acontecimento, incorporando-o à série discursiva:

[...] o gesto que consiste em inscrever tal discurso dado em tal série, a incorporá-lo a um "corpus", corre sempre o risco de absorver 0 acontecimento desse discurso na estrutura da série na medida em que esta tende a funcionar como transcendental histórico, grade de leitura ou memória antecipadora do discurso em questão. (Pêcheux, 2012, p.56)

0 acontecimento discursivo, a nosso ver, dialoga com as cenas de dissenso, uma vez que nelas são produzidos discursos marcados pela relação de identidade, imbricada na própria noção de sujeito que emerge nas cenas. 0 reconhecimento da agência do sujeito aparece, então, como uma necessidade para a teoria do discurso, pois "só por sua existência, todo discurso marca a possibilidade de uma desestruturação-reestruturação dessas redes e trajetos: todo discurso é potencialmente 0 índice potencial de uma agitação nas filiações sócio-históricas de identificação" (Pêcheux, 2012, p.56).

A comunicação organizacional, para dar conta da dinâmica das disputas discursivas na organização, deve ir além da comunicação da organização para seus públicos - organização comunicada - e incluir a organização comunicante, aquela dimensão comunicativa pertinente ao desequilíbrio e ao conflito que procura considerar a fala não autorizada "como processo de disputa de sentido no âmbito das relações organizacionais" (Baldissera, 2009, p.116). A partir dessa abertura da comunicação organizacional aos processos não controlados pela organização, Mafra e Marques (2017, p.92) avaliam que é possível apontar para "contextos relacionais em meio aos quais atividades conformadoras das práticas discursivas dos sujeitos ganham expressão e particularidade". Argumentam, pois, que "o sentido moral das práticas discursivas sobre 0 diálogo pode ser suposto pelos moldes discursivos que, em processo recursivo, são atualizados em e são atualizadores de cada um dos contextos relacionais constituidores da comunicação organizacional" (Mafra; Marques, 2017, p.93).

Daí decorre pensar que os conflitos envoltos na temática das cotas, pela perspectiva que apontamos aqui, derivam da relação entre diferentes sujeitos e que essas disputas e relações de poder constroem a comunicação da universidade. A dimensão da organização comunicante surge como uma "potência política na reorganização dos sujeitos" (Mafra; Marques, 2017, p.94). Ela é a via de acesso ao "âmbito do dissenso e da polêmica" (Mafra; Marques, 2017, p.94). Esses conflitos constituem-se como conflitos comunicacionais, em que a mobilização dos sujeitos emergentes provoca desequilíbrio na identidade da organização.

\section{DISCURSOS EM DISPUTA: NENHUM COTISTA A MENOS (NA UFRGS)}

Neste item, abordamos a cena de dissenso organizacional aberta com a apresentação, pela reitoria da UFRGS ao Conselho Universitário, de um documento intitulado Parecer 239, em agosto de 2016. 0 Parecer 239 visava modificar a política de ações afirmativas da UFRGS, no que diz respeito às regras de seleção dos estudantes cotistas no concurso vestibular da instituição², entre outros aspectos. 0 documento previa a limitação da concorrência dos candidatos inscritos pelo sistema de cotas às vagas destinadas à respectiva cota, sendo que, desde o início da política de ações afirmativas na UFRGS, oS

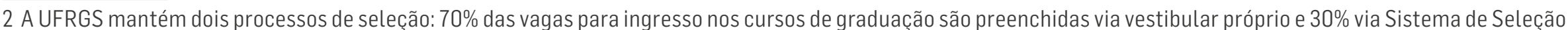

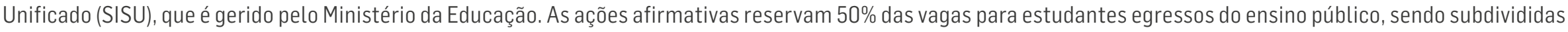
entre estudantes de renda familiar inferior a 1,5 salário-mínimo, autodeclarados pretos, pardos e indígenas e pessoas com deficiência. 
candidatos cotistas tinham o direito de concorrer primeiro às vagas de acesso universal, e somente ao não obter o índice para aprovação nessas é que eram classificados nas vagas reservadas 3 .

Diante da intenção que se materializa no documento, o parecer representava o restabelecimento do espaço dos que outrora tinham quase a totalidade das vagas da instituição em detrimento do acesso dos públicos da política. Ou seja, o significado da medida era o recrudescimento dos avanços democráticos da instituição. Esse foi o vetor do dissenso organizacional que se abriu à disputa sobre os caminhos da política. Além disso, somente a luta dos estudantes foi capaz de fixar tal significado ao parecer, que se apresentava como aprimoramento da reserva de vagas.

A partir do conhecimento da tramitação do referido parecer, defensores das cotas se mobilizaram e criaram um movimento social denominado Balanta - Nenhum Cotista a Menos. Este movimento promoveu uma série de reuniões de articulação e organizou a ocupação do prédio da reitoria da UFRGS na noite anterior à data prevista para a votação do Parecer 239 no Conselho Universitário.

Além das considerações acima sobre o caráter do documento, nossa análise recai sobre a (única) manifestação da reitoria realizada através do site institucional e as publicações da página do Facebook do movimento Balanta.

Do ponto de vista das manifestações oficiais, a organização pelo site, principal canal de comunicação da Universidade, optou pela estratégia do silenciamento. Da emissão do Parecer 239, ocorrida em agosto, até a ocupação da reitoria, em 22 de setembro de 2016, não houve qualquer posicionamento nesse espaço. Apenas no dia 23, já com a sede da administração ocupada pelo movimento, e com o acesso ao prédio vedado, a reitoria se manifesta em nota de esclarecimento, assinada pelo reitor Carlos Alexandre Netto, com o seguinte teor:

\footnotetext{
Não há, e em nenhum momento houve, por parte da Universidade Federal do Rio Grande do Sul, a intenção de retroagir em sua política de ações afirmativas;

Esta política foi implantada em 2007 e sempre esteve à frente do que a legislação nacional prevê;

A reitoria desta Universidade luta e é inflexível em relação a qualquer ato que possa representar recuo nos avanços já obtidos. A opção da UFRGS é transparente e imutável: o sistema de cotas não é passivel de retrocessos.

Desde a inclusão do parecer ํㅡㄹ 239/2016 na pauta do Conselho Universitário, e com pedidos de vista de conselheiros, verificou-se a necessidade de aprimoramento no texto. Isso foi feito e seria apresentado na reunião de hoje, 23 de setembro. A Emenda ao parecer está sendo distribuída ao Conselho Universitário e será apreciada na próxima reunião do CONSUN, agendada para o próximo dia 27 de setembro, às 8h30min, na Sala dos Conselhos - 2º andar da Reitoria. (Netto, 2016)
}

Nesse comunicado, percebe-se a intenção de deslegitimar a ação política de ocupação da reitoria, pois a "necessidade de aprimoramento no texto" já havia sido contemplada e a emenda seria apresentada na reunião do dia 23, que não ocorreu, devido à ocupação. Nota-se que os ocupantes são omitidos no texto, silenciamento que pode indicar o seu não reconhecimento, ou seja, eles não adquiriram, aos olhos da reitoria da universidade, a condição de sujeito. 0 ímpeto central do parecer, isto é, a restrição ao acesso dos cotistas (fim da concomitância), é minimizado, pois verificou-se necessidade de aprimoramento do parecer. É possível identificar o jogo discursivo implícito no título do texto - "Nota de esclarecimento" -, uma menção genérica, mas que se apresenta como verdadeira ante às demais versões que possam circular.

3 Esse sistema fez com que, em 2015, por exemplo, 60\% das vagas do vestibular tenham sido preenchidas por candidatos inscritos nas diferentes modalidades de cotas, ante os 50\% de vagas reservadas. Por desempenho, cerca de 400 cotistas preenchiam, a cada ano, vagas de acesso universal. A inversão dessa lógica representava a reserva de $50 \%$ das vagas a oriundos de escolas privadas, a maioria brancos e de renda superior à indicada na cota. 
O empenho da administração parece impor um sentido de normalidade irrompida não pelo conteúdo do parecer, mas pela ação dos manifestantes. A reitoria busca fechar a cena de dissenso e se direciona a deslegitimar o movimento de ocupação. Nessa disputa, vê-se que a organização comunicada reafirma as ações afirmativas como valor da organização, uma vez que o texto reconhece que a "Universidade luta e é inflexível em relação a qualquer ato que possa representar recuo nos avanços já obtidos" (Netto, 2016).

Na nota, há um processo de deslocamento do "Eu" para o "Ele", isto é, o texto assume a posição da reitoria da universidade, mas a apresenta em terceira pessoa, buscando promover um sentido de afastamento, um efeito de objetividade. Há, ainda, uma identidade entre o ele Universidade Federal do Rio Grande do Sul e o ele a reitoria dessa Universidade. A análise da cena permite compreender que o destinatário ocultado, o "outro", são os ocupantes do prédio da reitoria. Num nível mais abstrato, há também um destinatário que é o desejante da ordem, o estabelecido, o organizado.

0 contraponto ao fechamento do dissenso é feito pelo movimento Balanta ${ }^{4}$. Como coletivo político-estudantil negro, 0 Balanta pode ser encarado como sujeito emergente na "comunidade política" pela cena de dissenso. 0 movimento tem como principal canal de comunicação uma página no Facebook ${ }^{5}$, além da ação direta, que é uma forma de atuação política e de comunicação, pois há a produção de um acontecimento discursivo. 0 movimento ocupou a reitoria de 22 de setembro a 30 de setembro de 2016, período em que o acesso ao prédio foi vedado, impedindo a realização da reunião do Conselho Universitário, prevista para 23 de setembro. A entrada de conselheiros para a realização da sessão do Conselho Universitário, dia 27 de setembro, somente foi liberada após a negociação da pauta 6 . A ocupação foi nomeada pelos estudantes de Akilombamento, em referência às lutas do povo negro nos quilombos, reivindicando essa identidade histórica.

Em análise do movimento Balanta em sua segunda ocupação da reitoria, que ocorreu em março de 2018 e teve como objetivo o combate às fraudes na autodeclaração racial, Silva e Campos (2019, p.138) apontam que, enquanto movimento, o Balanta "construiu e fortaleceu um discurso de coletividade inserindo-se em diferentes tradições da resistência negra". Os autores destacam o uso do Akilombamento como processo de identidade: "a ação em si o insere na tradição dos protestos de políticaidentitária do chamado movimento negro contemporâneo iniciado nos anos 70. Em outro nível, ao evocarem a imagem do kilombo, inserem-se numa tradição de resistência de mais longa duração" (Silva; Campos, 2019, p.138).

Ao avaliarem a capacidade da comunicação do movimento, os autores ressaltam sua eficácia na construção de canais com a sociedade, o que colaborou para não serem criminalizados.

Para sequência da análise empírica, enfocamos materiais postados no período de 5 de setembro de 2016, quando é criada a página no Facebook do movimento, a 30 de setembro de 2016, quando se encerra a ocupação.

Podemos observar, nos materiais do Balanta, um nível de diálogo com a lógica instituída na organização, reforçando, em certa medida, o padrão organizacional. Isso ocorre com o reconhecimento do Conselho Universitário como legítimo âmbito para deliberação, além da ênfase em expressões que carregam o sentido da norma vigente, como "Parecer", "concomitância" e "acesso universal". Por outro lado, esses elementos cumprem um certo papel educativo, uma vez que difundem o conhecimento da terminologia burocrática, necessária para a ação político-institucional.

\footnotetext{
40 objetivo inicial do movimento era lutar contra a alteração proposta pelo Parecer 239, mas suas atividades passaram a incluir a denúncia de fraudes no sistema de cotas, que permitia que estudantes brancos ingressassem em vagas destinadas a negros, fraudando a autodeclaração étnico-racial, instrumento único até 2018 para a comprovação de pertencimento ao grupo de destino das vagas de pretos, pardos e indígenas.

5 A página contém publicações informativas, chamados para atos e outros materiais de divulgação das cotas e de cursinhos preparatórios para o vestibular. Disponível em: https://www.facebook.com/pg/balantanegritude. Acesso em: 27 nov. 2019.

6 Em 3 de outubro de 2016, o movimento se rearticulou para acompanhar a segunda fase das votações, sem que houvesse a ação de ocupação.
} 
Ao mesmo tempo, o movimento reforça a busca pelo reconhecimento da diferença, como é possível identificar no panfleto de mobilização distribuído na universidade e reproduzido na página do Facebook, que faz a chamada para uma aula pública que veio a ser o momento de concentração de pessoas para a ocupação da reitoria, ocorrida no final da tarde do dia 22 de setembro de 2016. 0 panfleto tem como título e subtítulo: "A UFRGS vai ser preta, indígena, periférica e popular. Nenhum cotista a menos, não à retaliação das ações afirmativas" (Balanta, 22 de setembro de 2016, grifo nosso).

Destaca-se que a referência à organização é na terceira pessoa - "eles" -, o que estabelece uma relação de diferença e cria um "nós" (pertencimento), como também se observa no primeiro texto explicativo publicado na página do movimento e em outras postagens como nas sequências 2, 3 e 4:

Sq. 2: Nós estudantes negros perdemos vagas para eles o tempo todo: quando fraudam, quando eles indeferem documentação porque não tem pessoal suficiente e eles tem pressa em fazer seus 11 chamamentos por ano, [...] quando nossas vagas que eram para ser garantidas por lei, mas são ocupadas por acesso universal e outras modalidades de alunos não autodeclarados, e quando eles insistem em apresentar meios de que aquele não é nosso espaço. (Balanta, 5 de setembro de 2016, grifo nosso)

Sq. 3: Diariamente sofremos retaliações dos que não nos querem aqui (que sabemos bem quem são), pois seguimos resistindo, tomando e ocupando o que é nosso por direito. (Balanta, 5 de setembro de 2016, grifo nosso)

Sq. 4: Vitória da negritude: As cotas não retrocedem!

Emparedamos a Reitoria e impedimos que se retirasse a possibilidade de os cotistas concorrerem concomitantemente nas vagas de cotistas e universais.

Mas a principal vitória que tivemos, foi a união do movimento negro na universidade. Saímos muito fortalecidos desse processo, e por isso fizemos a reitoria tremer. (Balanta, 30 de setembro de 2016, grifo nosso)

Nos textos da página do movimento, o "eles" se refere ao "estudante branco" -"perdemos vagas para eles o tempo todo", "ocupadas por alunos não autodeclarados" - e à UFRGS como organização - "eles têm pressa em fazer", "eles insistem em apresentar", "não nos querem aqui". Nesse jogo de pertencimento e demarcação de fronteiras entre "nós" e "eles" (Silva, 2000), o "nós" aparece como "nosso direito" e a "vitória que tivemos, foi a união do movimento negro. Saímos muito fortalecidos...". Em "A UFRGS vai ser preta", demarcam que a universidade ainda não é preta, ou seja, é um "não-eu", mas que pode ser um "eu".

As manifestações do movimento em publicações dão conta de expressar aspectos conflituosos do dia a dia dos estudantes, o que remonta ao não reconhecimento desse público, como se observa nas sequências 5 e 6 .

Sq. 5: Desde a implementação das Ações Afirmativas a UFRGS tenta nos arrancar à força pelo cansaço, pela exaustão e pela existência de políticas de permanência pífias e superficiais. Não nos querem aqui. (Balanta, 21 de setembro de 2016, grifo nosso)

Sq. 6: Por que a universidade se encastela e tenta aprovar medidas limitadoras do acesso popular à universidade sem diálogo com os movimentos sociais? Essa medida se caracteriza como um ataque elitista e acima de tudo racista, que visa dificultar ainda mais a acesso à esse espaço pela comunidade negra, indígena e periférica, que convive diariamente com o genocídio de seus corpos, mentes e espíritos. (Balanta, 22 de setembro de 2016, grifo nosso)

A emergência do movimento como sujeito no contexto organizacional representa também uma luta para que ele seja reconhecido como participante das decisões que lhe dizem respeito. 


\section{CONSIDERAÇÕES FINAIS}

Quando vistas em perspectiva histórica, as ações afirmativas nas universidades federais brasileiras só podem ser entendidas se consideradas as lutas dos movimentos negros por direitos. Assim, o caráter transformador das cotas, vivenciado pelos novos estudantes cotistas, proporciona uma fissura no padrão estrutural do sistema universitário. Se não é possível afirmar que houve uma ruptura com a lógica dos processos da instituição, pode-se constatar que a organização é constantemente tensionada a se atualizar, pois as universidades tendem a se fechar para o diferente, restringindo a atualização ao grau que convém às relações de poder que a conformam enquanto organização. 0 processo de luta não se exauriu com a aprovação das cotas e tem mostrado vitalidade para vigiar a implementação da política, podendo, inclusive, expandir seus horizontes.

Ao observar o processo de ocupação de 2016 sob o olhar das disputas discursivas transcorridas em uma cena de dissenso, pudemos perceber a importância do processo de formação de identidade para a constituição do sujeito em luta que busca modificar a forma da organização moderna. A análise a partir desse viés, na comunicação organizacional, é possibilitada pela noção de organização comunicante, pois abre espaço para mais vozes, diferentes da controlada, dando a ver as disputas e os atores concretos em relações de poder.

Os movimentos de pressão fazem contraponto à subjetividade preconizada pelo discurso organizacional. Os jovens se colocam na causa de uma coletividade, afirmando uma identidade pela diferença e questionando a organização, a partir da denúncia da desigualdade social e racial e de seu enfrentamento. Olhar para as ações afirmativas a partir da abordagem discursiva atenta ao conflito e pelo viés da organização comunicante permite refletir sobre o aprofundamento da transformação da universidade, bem como um caminho para a superação democratizante do padrão organizacional.

\section{REFERÊNCIAS}

BALDISSERA, Rudimar. Comunicação organizacional na perspectiva da complexidade. Organicom, São Paulo, v.6, n.10-11, p.116-120, 2009.

BALDISSERA, Rudimar. Da pesquisa em comunicação organizacional: fundamentos teóricos e metodológicos, práticas e críticas. In: MARQUES, Ângela C. S.; OLIVEIRA, Ivone de Lourdes; LIMA, Fábia Pereira (org.). Comunicação organizacional: vertentes conceituais e metodológicas. Belo Horizonte: Programa de Pós-Graduação em Comunicação Social, Universidade Federal de Minas Gerais, 2017. p.63-81.

BALDISSERA, Rudimar; MAFRA, Rennan. Discursos, identidades e relações de poder: dinâmicas e emergências em comunicação organizacional. In: CONGRESSO BRASILEIRO DE PESQUISADORES DE COMUNICAÇÃO ORGANIZACIONAL E RELAÇÕES PÚBLICAS, 13., 2019, São Paulo. Anais [...]. São Paulo: Abrapcorp, 2019. Disponível em: https://bit.ly/3zcTBqF. Acesso em: $29 a b r .2021$.

BALDISSERA, Rudimar. Tensões dialógico-recursivas entre a comunicação e a identidade organizacional. Organicom, São Paulo, n.7, p.229-243, 2007.

BRASIL. Lei no12.711, de 29 de agosto de 2012. Dispõe sobre o ingresso nas universidades federais e nas instituições federais de ensino técnico de nível médio e dá outras providências. Diário Oficial da União, Brasília,DF, 30ago.2012. Disponível em: https://bit.ly/2Y13zOl. Acesso em: 25ago.2021. 
DOMINGUES, Petrônio. Ações afirmativas para negros no Brasil: o início de uma reparação histórica. Revista Brasileira de Educação, Rio de Janeiro, n.29, p.164-176, 2005.

GRISA, Gregório Durlo. As ações afirmativas na UFRGS: uma análise do processo de implantação. 2009. Dissertação (Mestrado em Educação) - Universidade Federal do Rio Grande do Sul, Porto Alegre, 2009.

GUIMARÃES, Antonio Sérgio A. Acesso de negros às universidades públicas. Cadernos de Pesquisa, São Paulo, n.118, p.247-268, 2003.

LIJTERMAN, Eliana. Problemas de fronteira: reflexões sobre a relação entre o discursivo e o extradiscursivo na análise do discurso francesa. Bakhtiniana, São Paulo, v.12, n.2, p.57-78, 2017.

MAFRA, Rennan; MARQUES, Ângela. Organizações, modernidade e democracia na América Latina: diferenças desatualizadas e climas de estagnação. In: ENCONTRO ANUAL DA ASSOCIAÇÃO NACIONAL DOS PROGRAMAS DE PÓS-GRADUAÇÃO EM COMUNICAÇÃO, 28., 2019, Porto Alegre. Anais [...]. Porto Alegre: Compós, 2019. p.1-20. Disponível em: https://bit.ly/38saoKN. Acesso em: 25ago.2021.

MAFRA, Rennan; MARQUES, Ângela. Topografias do diálogo nos contextos organizacionais. In: MARQUES, Angela; OLIVEIRA, Ivone de Lourdes; LIMA, Fábia Pereira. Comunicação organizacional: vertentes conceituais e metodológicas. Belo Horizonte: Programa de Pós-Graduação em Comunicação Social, Universidade Federal de Minas Gerais, 2017. v.2., p.83-98.

MARQUES, Ângela; MAFRA, Rennan. 0 diálogo, o acontecimento e a criação de cenas em contextos organizacionais. Dispositiva, Belo Horizonte, v.2, n.2, p.2-20, 2014.

MISOCZKY, Maria Ceci. Da abordagem de sistemas abertos à complexidade: algumas reflexões sobre seus limites para compreender processos de interação social. Cadernos Ebape.br, v.1, n.1, p.1-17, 2003.

NETTO, Carlos Alexandre. Nota. UFRGS, 2016. Disponível em: https://bit.ly/3zlSHIk. Acesso em: 28out.2019.

ORLANDI, Eni Puccinelli. Análise de Discurso: princípio e procedimentos. 8.ed. Campinas: Pontes, 2009.

PÊCHEUX, Michel. Análise automática do discurso. In: GADET, Françoise; HAK, Tony (org.). Por uma análise automática do discurso: uma introdução à obra de Michel Pêcheux. 3.ed. Campinas: Editora da Unicamp, 1997. p.61-162.

PÊCHEUX, Michel. O discurso: estrutura ou acontecimento. 6.ed. Campinas: Pontes, 2012.

SILVA, Tomaz Tadeu da. A produção social da identidade e das diferenças. In: SILVA, Tomaz Tadeu da (org.); HALL, Stuart; WOODWARD, Kathryn. Identidade e diferença: a perspectiva dos estudos culturais. Petrópolis: Vozes, 2000.

SILVA, Wagner Machado da; CAMPOS, Deivison Moacir Cezar de. Os dois lados do espelho: a cobertura midiática e as publicações do coletivo negro Balanta no embate sobre as cotas na UFRGS. Prâksis, Novo Hamburgo, v.16, n.1, p.123-143, 2019. 